\title{
Factors affecting conversion of laparoscopic to open cholecystectomy
}

\author{
Raj Kumar Chhetri ${ }^{1}$, Muza Shrestha ${ }^{1}$, Ram Prasad Shrestha ${ }^{2}$ \\ ${ }^{1,1}$ Associate Professor, ${ }^{2}$ Senior Consultant Surgeon, \\ Department of Surgery, Manmohan Memorial Teaching Hospital (Proposed), Swoyambhu, Kathmandu Nepal.
}

Correspondence: Dr Raj Kumar Chhetri, Associate professor, Department of Surgery, Manmohan Memorial Teaching Hospital (P), Swoyambhu, Kathmandu Nepal.

Email: drrkchhetri@yahoo.com

\begin{abstract}
Introduction: Laparoscopic cholecystectomy is the gold-standard operation for the treatment of cholelithiasis. Various factors affect the conversion of laparoscopic to open cholecystectomy.

Methods: In this prospective analytical study one hundred and sixty consecutive patients who underwent laparoscopic cholecystectomy were studied to see the factors that affect the conversion to open cholecystectomy. Factors contributing to conversion of laparoscopic to open cholecystectomy were analyzed.

Result: In this study the conversion rate of laparoscopic to open cholecystectomy was $6.25 \%$. The most common cause for conversion was unclear anatomy and adhesion at the Calot's triangle and abnormal course of the cystic artery.

Conclusion: Proper knowledge about the anatomical variations of cystic duct and artery and timely conversion in cases of confusion can help prevent bile duct injuries during cholecystectomy.

Key words: Laparoscopic cholecystectomy, Conversion rate, Open cholecystectomy
\end{abstract}

\section{Introduction}

First described in 1882 by Langenbuch, open cholecystectomy has been the primary treatment of gallstone disease for most of the past century. But Mühe of Boblingen, Germany, who performed the first laparoscopic cholecystectomy, revolutionized the treatment of calculous gallbladder disease in 1985. Currently it is estimated that more than $90 \%$ of the cholecystectomies are performed laparoscopically. Laparoscopic cholecystectomy provides a safe and effective treatment for most patients with symptomatic gallstones. Advantages of laparoscopic cholecystectomy are earlier return of bowel function, less post-operative pain, improved cosmesis, shorter length of hospital stay, earlier return to full activity and decreased overall cost though there is $0.5-0.6 \%$ risk of biliary injury. ${ }^{17}$ Therefore, laparoscopic cholecystectomy is the goldstandard operation for cholelithiasis.

\section{Methods}

This is a prospective descriptive study conducted at Manmohan Memorial Hospital, Swoyambhu, over a period of one and half years (November 2013 to May 2015). There were total of one hundred and sixty patients who underwent laparoscopic cholecystectomy during this period. Detailed history and physical examinations including history of laparotomy, were done. All the patients then would undergo ultrasound scanning to evaluate the status of the gallbladder and the biliary system. Blood investigations included total and differential leucocyte count, Liver function test including serum bilirubin and alkaline phosphatase.

All patients with symptomatic gallstones, Gallbladder polyp of more than $1 \mathrm{~cm}$ or patients with biliary pancreatitis, acute cholecystitis of less than seventy two hours were included in the study. 
Preoperative history suggestive of acute cholecystitis of more than seventy two hours duration with thickened gallbladder wall of more than $4 \mathrm{~mm}$, gallbladder perforation, carcinoma of the gallbladder/ Gallbladder mass, dilated extrahepatic bile ducts or stone in the bile duct, deranged liver function test suggestive of obstructive jaundice, or persistently raised alkaline phosphatase were excluded from the study.

\section{Results}

The common age group affected is twenty to sixty years of age but $55 \%$ of the patients were of age group 21 to 40 years. (Figure 1) The eldest patient operated laparoscopically was of 87 years old female and youngest patient of 7 years female. Most of the patients (88\%) were female and only $12 \%$ were males. In $69 \%$ of the patients there were multiple stones and in $31 \%$ of the patients there was single stone.

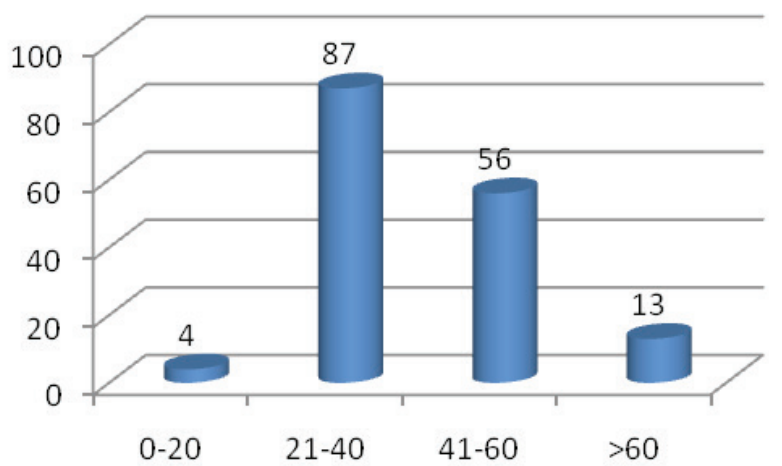

Figure 1: Age distribution of patients

Surgery was indicated for symptomatic gallstone in $43 \%$ of the patients while complications of the stone were the indication in $54.5 \%$ of the patients. In three percent of patients it was for the gallbladder polyp. (Table 1)

\section{Table 1: Indication for cholecystectomy}

\begin{tabular}{ll} 
Etiology & No of pts ( \% ) \\
\hline Symptomatic cholelithiasis & $69(43)$ \\
Chronic calculus cholecystitis & $54(34)$ \\
Acute cal cholecystitis & $28(18)$ \\
GB polyp & $5(3)$ \\
Biliary pancreatitis & $4(2.5)$
\end{tabular}

Table 2: Indications for conversion

$\begin{array}{ll}\text { Causes } & \text { No of pts } \\ \text { Adhesions in Calot's triangle } & 3 \\ \text { Unclear anatomy } & 3 \\ \text { Acute inflammation } & 1 \\ \text { Impacted stone at Hartmann pouch } & 1 \\ \text { Aberrant concealed artery } & 2\end{array}$

Total converted cases were ten out of 160 patients which accounts for $6.25 \%$. Main cause for conversion was unclear anatomy and the adhesion in the Calot's triangle $(60 \%$ of the converted cases). Other causes were impacted stone in the cystic duct compressing the hepatic duct (Mirizzi's syndrome), acutely inflammed gallbladder and aberrant concealed cystic artery (20\% of the converted cases). Among the converted cases males were four patients (ie $21 \%$ of the total male patients) and females were six (ie $4.25 \%$ of the total female patients).

\section{Table 3: Complications}

\begin{tabular}{ll} 
Complications & No of patients \\
\hline Bleeding & 2 \\
\hline Bile leak & 1 \\
\hline Port site infection & 4 \\
\hline Total & 7
\end{tabular}

Complications that we came across during the operation were aberrant concealed artery leading to bleeding during dissection at Calot's area in two patients which required conversion (Table 3). In both cases the course of the cystic artery was not in the usual pathway but rather posterior to the cystic duct. Postoperatively there was one bile leak which necessitated laparotomy on fourth postoperative day. In this patient the cystic duct was wider than usual and short. The reason for the bile leak was due to incomplete clipping of the cystic duct. Four patients had superficial surgical infection at the umbilical port site which was managed conservatively

\section{Discussion}

Laparoscopic cholecystectomy is now the established goldstandard method of treatment for the gallstone disease. There are factors, which influence in the conversion of laparoscopic to open cholecystectomy. 
In our study the female patients constituted $88 \%$ of the total patients but in the literature it is lower. ${ }^{6,7,16}$ Age groups most commonly affected is from 21 to 40 years which is similar to other studies. ${ }^{7,16}$

In our study conversion rate was $6.25 \%$ which is comparable to literature. Conversion rates vary from as low as $2.5 \%$ to as high as $26.1 \%$. $^{2,4,6,8,12,15}$

Factors for conversion to open cholecystectomy in our study were adhesion around Calot's triangle obscuring the anatomy, abnormal arterial course and acute cholecystitis. Male patients had higher conversion rate as compared to the female patients ( $21 \%$ males and $4.25 \%$ females).

In a review of ninety-one studies in Medline search, the rate of conversion varied from 0.18 to $30 \% .{ }^{16}$ In this review the most common causes for difficulty were male patients, increased age of the patient, acute and thick wall chronic cholecystitis, wide and short cystic duct, cholecystodigestive fistula, previous upper abdominal surgery, obesity, liver cirrhosis, anatomic variation, cholangiocarcinoma and low surgeon's caseload. Similarly, infiltration/fibrosis of Calot's triangle and adhesions has also been reported to be a common cause of conversion. ${ }^{5}$

Postoperative complication rate in our study was $4.38 \%$, which is comparable to that reported in the literature. ${ }^{6,7,9,10}$ Bleeding around the Calot's triangle due to abnormal vessel anatomy and adhesions, post operative bile leak from cystic duct stump and port site infection were the complications we came across in our study. There was no mortality in our study.

In a prospective review during the early days of laparoscopic cholecystectomy from Brunei found the morbidity of 5\% with one ductal injury $(0.5 \%)$ and one mortality $(0.5 \%)$ in an 87 years woman who developed postoperative bronchopneumonia. $^{9}$ A review of 2200 laparoscopic cholecystectomies as the treatment in gallstone disease published in 1994 reported a complication rate of $3.6 \%$ with port site infection in $2.2 \%$ patients, postoperative bleeding in $0.4 \%$ and hepatocholedochus in $0.4 \%$ patients and the mortality was $0.1 \% .^{12}$

\section{Conclusion}

Proper preoperative workup and investigation can help to predict conversion during cholecystectomy. Male gender, patients with acute cholecystitis or history of cholecystitis in the past (leading to adhesions in the Calot's triangle) and Ultrasound finding of impacted stone in the cystic duct (leading to Mirizzi's syndrome) can affect conversion to open cholecystectomy. Proper knowledge about the abnormal course of the cystic artery can also affect the outcome as in our study where it was observed in two patients which needed conversion.

\section{References}

1. Tang B, Cuscherieri A. Conversions during laparoscopic cholecystectomy: risk factors and effects on patient outcome. $\mathrm{J}$ gastrointest Surg. $2006 \quad$ Jul-Aug; 10(7):1081-91. https://doi.org/10.1016/j.gassur.2005.12.001 PMid: 16843880

2. Wiebke EA, Pruitt AL, Howard TJ etal. Conversion of laparoscopic to open cholecystectomy. An analysis of risk factors. Surg Endosc. 1996 Jul;10(7):742-5. https://doi.org/10.1007/ B F 00193048 PMid:8662431

3. Liu CL, Fan ST, Lai EC, etal. Factors affecting conversion of laparoscopic cholecystectomy to open surgery. Arch Surg. 1996 Jan; 131(1):98-101. h t t p s : / / d o i. o r g / $100.10001 /$ a r ch surg. 1996.014301301000022 PMid:8546587

4. Fried GM, Barkun JS, Sigman HH, etal. Factors determining conversion to laparotomy in patients undergoing laparoscopic cholecystectomy. Am J Surg. 1994 Jan; 167(1):35-9. https://doi.org/10.1016/0002-9610(94)90051-5

5. HJ van der steeg, S. Alexander, S. Houterman, etal. Risk factors for conversion during laparoscopic cholecystectomy- experiences from a general teaching hospital. Scandinavian Journal of Surgery 2011;100: 169-173, https://doi.org/10.1177/145749691110000306 PMid:22108744

6. Malla BR, Shrestha RKM. Laparoscopic cholecystectomy and conversion rate. Kathmandu Univ Med J. 2010;9(32):367-9

7. 7. Kanaan SA, Murayama KM, Merriam LT, etal. Risk factors for conversion of laparoscopic to open cholecystectomy. J Surg Res. 2002 Jul; 106(1):20-4 https://doi.org/10.1006/jsre.2002.6393 PMid:12127803

8. Ballal M, David G, Willmott S, etal. Conversion after laparoscopic cholecystectomy in England. 
Surg Endosc. 2009 Oct; 23(10):2338-44 https://doi.org/10.1007/s00464-009-0338-1

9. PMid:19266237

10. Kok KY, Mathew VV, Tan KK, etal. A prospective review of laparoscopic cholecystectomy in Brunei. Surg Laparosc Endosc. 1998 Apr; 8(2):120-2. https://doi.org/10.1097/00019509-199804000-00008 PMid:9566565

11. Paredes Cotore JP, Carrillo Pallares A, Ramirez Felipe JA. Laparoscopic cholecystectomy in Spain: multicentric study of 2432 patients. Rev Esp Enferm Dig. 1994 Jan; 85(1):19-26. PMid:8185998

12. Kama NA, Doganey M, Dolapci M, etal. Risk factors resulting in conversion of laparoscopic cholecystectomy to open surgery. Surg Endosc. 2001 Sep; 15(9):965-8. https://doi.org/10.1007/s00464-001-0008-4 PMid:11443475

13. LohdeE, Raude E, Raude H, etal. Experiences with 2200 laparoscopic cholecystectomies as the treatmentconcept in gallstone disease. Zentralbl Chir. 1994; 119(6):371-7. PMid:8091874

14. Morlang T, Umscheid T, Stelter WJ. Laparoscopic cholecystectomy: prospective study of 1775 unselected patients. Zentralbl Chir. 1995; 120(5):353-9. PMid:7610721

15. Zang WJ, Li JM, Wu GZ, etal. Risk factors affecting conversion in patients undergoing laparoscopic cholecystectomy. ANZ J Surg. 2008 Nov; 78(11):973-6 https://doi.org/10.1111/j.1445-2197.2008.04714.x PMid:18959695

16. GabrialR, KumarS, ShresthaA.Evaluation of predictive factors for conversion of laparoscopic cholecystectomy. Kathmandu Univ Med J. 2009 Jan- Mar; 7(25):26-30 https://doi.org/10.3126/kumj.v7i1.1761

17. Hussain A. Difficult cholecystectomy: current evidence and strategies of management. Surg Laparosc Endosc Percutan Tech. 2011 Aug; 21(4):211-7 https://doi.org/10.1097/SLE.0b013e318220f1b1 PMid:21857467
18. Michail Karanikas, Ferdi Bozali, Vasileia Vamvakerou, etal. Biliary tract injuries after lap cholecystectomy - types, surgical intervention and timing. Ann Transl Med 2016; 4(9):163 https://doi.org/10.21037/atm.2016.05.07 PMid:27275476 PMCid:PMC4876287 